\title{
Minimizing the losers: regime satisfaction in multi-level systems
}

\author{
Katharina Holzinger • Andrea Schneider • \\ Klaus W. Zimmermann
}

\begin{abstract}
The political blessings of federalism are the core of our discussion. These benefits can be operationalized as a decrease in the number of outvoted people in a federal system with majority voting which is an important source of regime satisfaction. The approach originates from the work of Roland Pennock who developed a similar methodology about 50 years ago. Measuring inverse regime satisfaction by the maximum of the outvoted, our results show that regime satisfaction decreases if total population rises. Additionally, the share of the maximum outvoted decreases if the top level cooperates with lower-level jurisdictions and if all jurisdictions of one level are included. However, while the inclusion of an additional lowest-level jurisdiction always reduces the relative number of the outvoted, the effect of including other levels depends on the structure of jurisdictions already intertwined.
\end{abstract}

Keywords Federalism - Decentralization - Multi-level systems · Regime satisfaction

JEL Classification $\mathrm{H} 77 \cdot \mathrm{D} 72$

\author{
K. Holzinger $(\bowtie)$ \\ Department of Politics and Public Administration, University of Konstanz, Konstanz, Germany \\ e mail: katharina.holzinger@uni konstanz.de \\ A. Schneider \\ Institute of Public Economics I, University of Münster, Münster, Germany \\ e mail: andrea.schneider@uni muenster.de \\ K. W. Zimmermann \\ Institute for Economic Policy Research, Helmut Schmidt University Hamburg, Hamburg, Germany \\ e mail: kwzi@hsu hh.de
}




\section{Introduction}

In debates on decentralization and federalism, positive attributes have been generally ascribed to federal systems: (i) being able to avoid welfare losses at the lower levels which would otherwise occur due to central and highest-level decisionmaking (the decentralization theorem) (ii) a better matching of collective supply with regional and local demand and (iii) constituting a search and discovery procedure for institutional innovations (von Hayek 1968) on account of the multiplicity of projects going on in competing jurisdictions. In addition, however, multi-level systems offer an important political component which is seldom addressed explicitly and, therefore, deserves some closer inspection: they serve to the satisfaction of the voters and foster their satisfaction with the political system or their regime satisfaction without which democratic systems would hardly be sustainable.

Among the few economists who have taken up this special aspect is Richard E. Wagner, a prominent representative of the political economy literature who in a simple case to be presented later showed that decentralized decision-making reduces the number of outvoted and, therefore, enhances regime satisfaction. His way of thinking refers to the work of J. Roland Pennock who dealt with this question already in 1959. Pennock's view of federalism can be illustrated best with the following quotation: "it is a major advantage of federalism that the decentralization of voter decisions makes for the satisfaction of more of the voters more of the time than if they acted as a single unit (1959, 149)". Multi-level systems and federal systems are always multi-level with 'classical' federalism as the simplest form consisting of two levels with state-like quality have the particular advantage of reducing or even minimizing the number of outvoted, and this will be the main topic of this contribution. It suffices to say that reducing the number of outvoted is only one political criterion to design an optimal federal structure even if that design incorporates economic thinking. There are a couple of purely economic ones which have to be considered in addition for an optimal design of an institutional structure like homogeneity of preferences, catching spill-overs, increasing returns, and so on. But here we will concentrate on a single question to be answered: if there is a multi-layered system, which would be the best strategy to minimize the share of the outvoted? Since in a multi-level system the levels can and should not perfectly sealed off, overlapping functions and competences require joint decisions of jurisdictions at different levels which will appear as various intertwinings in our model. Those variable intertwinings constitute the strategic variable in our model to minimize the share of the outvoted.

The article is structured as follows: in Sect. 2 we will look at the literature which can be seen as basic for the study of federal systems as far as the political functions of federalism are concerned. In Sect. 3 we present the original method of analyzing decisions in federal systems with an emphasis on the outvoted as developed by Pennock. In Sect. 4 we examine multi-level systems in detail by presenting some formal considerations about the interaction of jurisdictions and levels with regard to the problem of the absolute and relative number of the outvoted. The paper finishes with a conclusion in Sect. 5. 


\section{From divisive bickering to regime satisfaction}

"In political practice, the net effect [of federalism] is the existence of two sets of governments in the same place governing the same people. Not surprisingly, conflicts between the two sets have characterized all modern federalisms (Riker and Schaps 1957, 276)". This is the specific view of American federalism by the prominent political scientist William Riker. Riker and Schaps radically foreshorten the concept of federalism to 'divisive bickering' and 'lack of integration of policies between the centre and the periphery', and argue that the political parties tend to aggravate these problems instead of alleviating them. ${ }^{1}$ To demonstrate this, they developed an 'index of disharmony' which can be explained quite simply: if the Democrats in the U.S.A. are in charge of the Federal Government but the Republicans are in charge in most of the states, this index will be high, et vice versa. With the help of this indicator they examined the period 19371956 and found that there were significantly more disputes submitted to the Supreme Court when the index was high. In comparison to Australia and Canada they ascertained that "a federalism with more than two significant parties, relatively few states and a parliamentary government is almost certain to experience severe federal disharmony (Riker and Schaps 1957, 288)".2

In a similar vein, more recent theories in political science stress the importance of heterogeneous preferences, conflict and the problems of reaching agreement in federalist systems. Legislative federalism (e.g. Rose-Ackerman 1981), the theory of Politikverflechtung (Scharpf 1988), and veto player theory (Tsebelis 2002) are the most prominent ones. Rose-Ackerman develops a formal model in which she shows that policy choices can in fact change as a consequence of a federal structure as compared with a unitary system and given the same policy preferences of the citizens. In Rose-Ackerman's model, federalism matters just because the status quo in the member states implies heterogeneous preferences between the lower-level jurisdictions. Politikverflechtung describes the necessities of vertical and horizontal co-operation in a federal system. Scharpf (1988) has coined the term 'joint decision trap' to describe the negative consequences of Politikverflechtung for German and European federalism. Joint decision-making in an institutional decision-making structure of two or more levels can lead to systematically inefficient and inadequate decisions and to the incapability to change the institutional conditions that lead to

\footnotetext{
${ }^{1}$ It is rather astonishing that Riker who devoted a lot of work to this topic (Riker 1964, 1987) on the one hand, attributes such negative traits to federalism, and on the other hand writes: "Does federalism make any difference in the way people are governed? And the answer appears to be: Hardly any at all (Riker 1969)". Several reasons are discussed in the literature (Volden 2004) but in the end it is clear that Riker revised his position towards federalism gradually during his lifetime culminating in: "Considering all the federations there have been in the world, I believe that federalism has been a significant force for limited government and hence for personal freedom" (Riker 1996).

${ }^{2}$ Additionally they took a side glance at the then Federal Republic of Germany at that time: "The government of West Germany is just such a federalism [...]. From a German point of view at least, it is unfortunate that the German basic law was so blithely fashioned as a federalism without consideration of the potential disharmony to be faced. Perhaps, if West and East Germany are ever united, German constitution writers will have a second chance". Half a century later we know that the opportunity of German unification was not really taken up when it suddenly arose.
} 
these results. Finally, it is typical for multi-level systems to have a large number of veto players. The more consensus is required, the more difficult it is to find an agreement (Tsebelis 2002). Both the joint decision trap and veto player theory imply that policy change and constitutional change are difficult to achieve in multi-level systems.

Riker and Schaps as well as Scharpf and Tsebelis only looked at one side of the coin the apparent difficulty in a federal system of reaching a consensus. However, it seems to be fair to contrast this perspective with the various advantages of federalism so that Pennock $(1959,148)$ in his follow-up article to Riker and Schaps (1957) concludes: “[...]'bickering' may be a fairly harmless matter and at least not an inordinate price to pay for the advantage of federalism". Roland Pennock whose way of thinking will be the starting point for our considerations here especially points to the fact that federalism "not only divides powers, it divides functions. In this division of functions lies the possibility of maximizing satisfaction in a way a uniform national treatment could not accomplish (Pennock 1959, 149)." How Pennock proved this methodically is rather ingenious and made us use an analogous procedure, but it has also stimulated other authors. ${ }^{3}$ One of them is Richard E. Wagner who has taken up this way of thinking at several places (Wagner 1971, 19, Wagner 1973, 62, Wagner 2001, 23, Wagner 2007) and from whom the following example, presented here in a tabular form (Table 1), is derived (Wagner 1971, 19).

A state may consist of two regions $\mathrm{X}$ and $\mathrm{Y}$ with the same population figures (50.000), and two projects $\mathrm{A}$ and $\mathrm{B}$ are up for election by majority rule.

If a central decision of all voters of the state is prescribed, project A would win and the outvoted minority rate is $45 \%$. However, if one lets the regions decide decentrally for themselves, project $\mathrm{A}$ will be chosen in region $\mathrm{X}$ and project $\mathrm{B}$ in $\mathrm{Y}$, and the overall rate of the outvoted would only be $35 \%$. So, federalism possesses an eminently important political component besides the well-known advantages of decentralization and federalism (cf. Oates 1972, 1999; Kahlenborn and Zimmermann 1994; Holzinger 2000; Wagner 2007). This eminently important political component of federalism consists of its ability to diminish the aggregate rate of the outvoted which will be the more distinct the more heterogeneous the preferences of the regional populations are. Being outvoted leaves individual citizens dissatisfied in a double way. First, there is the cost of not getting the government and policies one has voted for, i.e., not being able to have one's own preferences fulfilled, an aspect that has been dubbed 'external costs' by Buchanan and Tullock (1962). Second, being outvoted may cause pain just because of being outvoted and belonging to the minority. Minimizing the losers is thus a normatively desirable property of a political system because it reduces 'disharmony and frustration' (Pennock), and, as we know today, makes the people happier (Frey and Stutzer 2001). Therefore, central within the properties of 'minimizing the losers' is that it improves regime satisfaction on a collective level and fosters the preference of the people for democratic procedures. The concept of regime satisfaction is primarily a

\footnotetext{
${ }^{3}$ It is rather amazing that Bueno de Mesquita et al. (2003) in their much cited book do not refer to Pennock although they apply his method as a kind of mirror image in their study: in their Selectorate Theory the concept of the minimum winning coalition (being originally a Riker invention) plays the major role, and that is exactly the contrary to the maximum number of the outvoted.
} 
domain of Public Opinion Research, but is used analogously in Political Science and Economics under the heading 'satisfaction with democracy' (SWD) (Cusack 1999; Wagner et al. 2009). Generally it is presumed that high-quality institutions such as the rule of law, good governance, accountability of the political system, and the absence of corruption, help to increase SWD (Castillo 2006). In more theoretical approaches based on Easton (1975), Norris (1999) and Dalton (1999) developed a five-level system of political support comprising 'satisfaction with democratic process'. However, they did not distinguish it from the perceived performance of the current government. Recently, Haerpfer (2007) proposed to revise that main-stream system by inserting 'satisfaction with current government' as a new level ${ }^{4}$ so that the next higher level could be separated as 'satisfaction with democracy'. Here, based on regime institutions at a lower level the performance of the current democratic regime is central comprising the constitutional framework, governments and parliaments, the judiciary, and the media. ${ }^{5}$ And it is just here that a strategy like 'minimizing the losers' finds its appropriate place: generally those voters whose party or candidate lost the election express lower confidence in the government (Anderson and Tverdova 2001) which at a higher level leads to decreased satisfaction with democracy (Anderson and LoTempio 2002) and may even destabilize it. ${ }^{6}$ Therefore, losers are 'the crucial veto players of democratic governance' (Anderson et al. 2005, 7) or said in another way: "the viability of electoral democracy depends on its ability to secure the support of a substantial proportion of individuals who are displeased with the outcome of an election (Nadeau and Blais 1993, 553)". What is valid empirically for elections per se, is actually multiplied in a multi-level governance system: here, not only a multitude of elections on different institutional levels occurs, but the governments of the jurisdictions at the respective levels do not act separately with increased regularity but are intertwined in many ways. In fact, and in contrast to Pennock this kind of federalism does not divide powers but integrates them. Here, this paper wants to fill a gap initially from a theoretical perspective: under the fiction of direct-democratic voting as in our model the question has to be answered how the number of losers in polls can be minimized and what structure of intertwinings of institutions on the various levels performs best to reach that goal. ${ }^{7}$

\footnotetext{
${ }^{4}$ The Haerpfer system consists of six levels: level 1 political actors; level 2 regime institutions; level 3 performance of current government; level 4 performance of current democratic regime, measured as satisfaction with democracy SWD; level 5 regime principles; level 6 political community.

${ }^{5}$ Besides those institutions SWD may also be positively influenced by the utility that can be derived from the act of voting itself (procedural utility); here, the process of voting is relevant, not the result (Frey and Stutzer 2004).

${ }^{6}$ For a comprehensive discussion see the recent paper by Curini et al. (2010).

7 The empirical literature on this topic is usually ahistoric with regard to the sequence of elections and the history of voters as losers or winners (with the exception of Curini et al. 2010). It is plausible to assume that the fact of being outvoted exerts negative effects on SWD in the long run if losing polls accrues with above chance frequency and/or polls are regularly lost related to topics that are perceived as important in contrast to polls won related to unimportant topics. Both aspects can also be subsumed under the heading of cleavage theory proposing that only cross cutting cleavages can secure the existence of a democratic system in a nation state in the long run (Rabushka and Shepsle 1972). However, this aspect is usually ignored in the literature.
} 


\section{Pennock's approach}

Richard Wagner's example above is a trimmed version of Roland Pennock's approach, which we will discuss here in a shortened form too. The approach can also be linked with several paradoxes of public choice theory even if these paradoxes are only on the fringe of our topic. The general form of these paradoxes is the referendum paradox (Merlin and Valogne 2004), hinting at the fact that the winner in terms of parliamentary seats does not necessarily have the majority of votes the Bush versus Gore case in the presidential election of 2000. A special case of this general paradox is Anscombe's paradox (Anscombe 1976) where a majority of voters disagrees with a majority of proposal results. However, this paradox would become relevant only if every decision on all levels would imply a different topic. Just the contrary is the case in multi-level decision-making where various levels decide mutually on the same topic as in our model of minimizing the losers, operationalized by the maximum number of outvoted and its shares.

Pennock, the original inventor of this method, considers federal systems that consist of two states. These states are predominantly Democratic (characteristic A) or predominantly Republican (characteristic C). ${ }^{8}$ Whereas at a joint election at the federal and the state levels the voters have two votes (as they elect two governments, one for each level), they only have one in a unitary system. In order to make both systems comparable it is necessary to make an assumption about how a vote at the states' level would have been cast in a unitary state. This is in line with Riker and Schaps (1957, 277) emphasizing that parties not only bear the same names at the state and federal levels but also have to be seen as monolithic. Taking this into account, a Republican vote at the state level for instance, may be interpreted as a potentially 'frustrated' vote in a unitary state if the Democrats win the election.

To give an example, if in the simplest case 40 votes were given to the losing party at the federal and state level, then there will be 80 frustrated votes. In a unitary state there should be 80 'frustrated' votes also since in that case each voter should have the equivalent of two votes to secure the comparability of the results. If we now assume 100 voters per state and postulate that decisions at the federal and state level are of equal value from the perspective of the voters, the election outcome can be illustrated by Table 2 .

This should be explained a little: in a first step in both states the federal level is voted for. Here State A has a stronger vote for the Democrats than State B for the Republicans so that the president will be a Democrat but 95 voters will be frustrated 20 in State A and 75 in State B. Due to the assumption that parties are monolithic (and that there are no non-voters) the vote-structure is the same at the state level as at the federal level: in State A, the Democrats get the majority and nominate the governor resulting in 20 frustrated Republican voters while in State B the Republicans win the election leaving behind 25 frustrated Democratic voters so

\footnotetext{
${ }^{8}$ Pennock originally experimented with different forms of unions using the criteria of moderately Democratic (characteristic B) and moderately Republican (characteristic D) in addition. Our excerpt from his Table 1 (Pennock 1959, 150) relates to his '1st union' consisting of states with Democratic and Republican dominance.
} 
Table 1 Election outcome (Wagner 1971, 19)

\begin{tabular}{llll}
\hline Regions & Projects & & \\
\cline { 2 - 4 } & A & B & Sum \\
\hline $\mathrm{X}$ & $35 \mathrm{~T}$ & $15 \mathrm{~T}$ & $50 \mathrm{~T}$ \\
$\mathrm{Y}$ & $20 \mathrm{~T}$ & $30 \mathrm{~T}$ & $50 \mathrm{~T}$ \\
Sum & $55 \mathrm{~T}$ & $45 \mathrm{~T}$ & $100 \mathrm{~T}$ \\
\hline
\end{tabular}

Table 2 (Frustrated) votes in the federal state

\begin{tabular}{|c|c|c|c|c|c|c|c|c|c|}
\hline & \multicolumn{3}{|c|}{ Federal level } & \multicolumn{5}{|c|}{ State level } & \multirow[t]{2}{*}{ Total frustrated } \\
\hline & $\begin{array}{l}\text { Dem. } \\
a\end{array}$ & $\begin{array}{l}\text { Rep. } \\
b\end{array}$ & $\begin{array}{l}\text { Frust. votes } \\
c\end{array}$ & $\begin{array}{l}\text { Dem. } \\
d\end{array}$ & $e^{\operatorname{Rep}}$ & & $\begin{array}{l}\text { Frust. } \\
f\end{array}$ & & \\
\hline \multicolumn{10}{|l|}{ 1st union } \\
\hline State A & 80 & 20 & 20 & 80 & \multicolumn{2}{|l|}{20} & 20 & \multicolumn{2}{|r|}{40} \\
\hline State B & 25 & 75 & 75 & 25 & 75 & & 25 & \multicolumn{2}{|r|}{100} \\
\hline Totals & 105 & 95 & 95 & 105 & 95 & & 45 & \multicolumn{2}{|r|}{140} \\
\hline \multirow{2}{*}{\multicolumn{4}{|c|}{$\begin{array}{l}\text { Table } 3 \text { (Frustrated) votes in the } \\
\text { unitary state and profit from } \\
\text { federalism }\end{array}$}} & \multicolumn{5}{|c|}{ Presumed frustrated votes } & \multirow{2}{*}{$\begin{array}{l}\text { Profit from } \\
\text { federalism } \\
k\end{array}$} \\
\hline & & & & \multicolumn{2}{|c|}{$\begin{array}{l}\text { Fed. level } \\
h\end{array}$} & \multicolumn{2}{|c|}{$\begin{array}{l}\text { State level } \\
i\end{array}$} & $\begin{array}{l}\text { Total } \\
J\end{array}$ & \\
\hline & & & \multicolumn{7}{|l|}{ 1st union } \\
\hline & & & State A & 20 & \multicolumn{3}{|c|}{20} & 40 & \\
\hline & & & State B & 75 & \multicolumn{3}{|c|}{75} & 150 & \\
\hline & & & Totals & 95 & \multicolumn{3}{|c|}{95} & 190 & 50 \\
\hline
\end{tabular}

that the total number of frustrated voters at the state level adds up to 45 . Since 95 Republicans are frustrated in the presidential election at the federal level, the total number of frustrated votes in this two-level system amounts to 140 and the total share of frustrated votes to 140 out of $400(35 \%)$ due to the fact that each voter has two votes (for two levels).

Focusing on a unitary state the result of the election led to a Democrat as president, which means that 95 Republican voters are frustrated (thus, columns $\mathrm{h}$ in Table 3 and $\mathrm{c}$ in Table 2 are identical). However, in a unitary state there are no elections at the state level because there are no states (only sorts of administrative districts). However, to make both systems comparable the aggregate number of votes in the federal state must equal the aggregate number of votes in the unitary state. Therefore, the votes at the state level must be doubled or expressed in another way: the 95 frustrated Republicans from column e must be added. That adds up to 190 frustrated votes all together and thus 50 frustrated votes more in the unitary than in the federal system. Those 50 votes represent the 'profit from federalism'. Pennock focuses on the absolute number of frustrated votes, i.e., the totals of columns $g$ and $\mathrm{j}$, and calls it the 'index of frustration' which is a somewhat dubious choice because of its missing comparability. It would be better to assign this name 
to the share of frustrated votes which amounts to 190 out of $400(47.5 \%)$ meaning that there are 12.5 percentage points more frustrated votes in a unitary than in a federal state.

Pennock's method is relatively simple but he arrives at striking results. His calculations show that the profit from federalism is highest the more diverse voter's preferences are. He also concludes that "it is disparity among the results in the different states that produces profit for federalism" (1959, 151). In all, Pennock's work is admirable considering that it appeared 13 years before Wallace Oates published his Fiscal Federalism (1972). But Oates, as well as most of his followers, analyzed the political benefit of federalism only marginally, so there is something left to do.

\section{Patterns of maximum outvoted: searching for regime satisfaction}

In designing our model we postulate a four-level structure. This is not self-evident and, for example, Puchala (1972) assumed three levels in terms of subnational, national and supranational for the EU. We in contrast, adhere to the structure proposed by Wallace $(2005,78 f)$ and postulate a four-level system consisting of the supra-national, national, regional and local levels which is somewhat adjusted to our problem. ${ }^{9}$ Furthermore, we assume that all jurisdictions at the same level have the same population size. This, evidently, is a remarkable simplification but it has the great advantage of excluding different results concerning the maximum number of outvoted if at the single levels there are varying interweavings between jurisdictions, or said in another way, varying clubs (Buchanan 1965; Zimmermann and Schemm-Gregory 2005). Finally, we assume, as Wagner did in his example, two projects which have to be voted on, ${ }^{10}$ and that such voting happens according to majority rule as a direct-democratic procedure. In fact, most decisions in actual federal systems are taken by representatives and not by direct-democratic voting. This is true even for Switzerland (and the more for the EU), a federal system in which referenda play a great role at all three levels of government. Our assumption serves, however, as an approximation of the basic majority principle which is constitutive for democracy. Neglecting representation ${ }^{11}$ is necessary to exclude the principal-agent problems inherent in the relationship between voter and politician in order to isolate the pure effects of federalism.

Despite these model-specific restrictions it goes without saying that the EU has served as background for the development of our model. There are two reasons for that, a theoretical and a political one. The first and theoretical is that a model of Multi-Level Governance (MLG) as a snapshot of the current state of the EU had

\footnotetext{
${ }^{9}$ Helen Wallace originally constituted a system of four levels: global, European, national and local.

${ }^{10}$ Evidently, projects have to be financed but we exclude the burden sharing aspect from our considerations here; if we wanted to discuss it we would surely have to refer to Olson (1969) and his principle of 'fiscal equivalence'.

11 The distortions introduced to multi level systems by various modes of representation and decision making at different levels of government are discussed in Holzinger (2008).
} 
been developed in Marks et al. (1996) and Hooghe and Marks $(2001,2003)^{12}$ which found a lot of attention not only among political scientists. According to them (1996, 372) "policy-making in the EU is characterized by mutual dependence, complimentarity functions and overlapping competencies". Following these authors (1996), MLG is based on three central premises: (a) In the MLG model the competences are distributed to different levels and are exercised by different actors. The European institutions (Parliament, Commission and the European Court of Justice) are independent members within this multi-level system and on no account only agents of the principals in the form of the member states. (b) The supranational decision-making system causes a substantial loss of importance for the national governments, because increasingly less the unanimity principle with its tendency towards the smallest common denominator is applied. (c) The political decision levels are not isolated as in classical federalism, there is no clear separation between national and supranational levels any more. This means that regions and subnational states are operating on the national as well as on the European level, but that the supranational level meddles with the national and subnational levels too. It is obvious that such flexible decision-making structures can be designed to fulfill certain goals, for instance with regard to minimizing the losers or maximizing regime satisfaction.

The second and political reason is that the European Commission (2001) itself launched a very similar strategy in its White Paper of 2001 on "European Governance". The arguments of the Commission circle around the concepts of transparency, participation, effectiveness, coherence and accountability. The leading idea consists of reducing the lack of information the citizens obviously have with regard to working procedures and responsibilities of the EU institutions leading to a considerable degree of alienation of the citizens from the EU project as a whole. Another big point in the White Paper is the more forceful integration of as much as possible actors into a common decision and implementation framework leading to a new culture of consultation and dialogue especially with regard to regional and local actors. Furthermore, the Commission request a debate about the reversion to the true core competencies of the EU institutions. It demands from itself to take over control of the whole policy implementation process which Scharpf (2001, par. 5) interprets as 'the creation of a benevolent dictatorship'. Finally, and understandably not mentioned in the White Paper, the enhanced inclusion of regional and local actors into the policy process serve as an instrument to internalize positive image spill overs in favor of the EU institutions Recent official surveys of the EU, Eurobarometer 70 (European Commission 2009a) and Special Eurobarometer 307 (European Commission 2009b) clearly reveal that only a minority of the people in Europe attest a positive image to the EU, and that among the European institutions the Commission finds the lowest trust, expressed also in the image of 'Brussels' as a mammoth administration far away from the people and their needs and wishes. So, a stronger inclusion and participation of lower levels is not as

\footnotetext{
${ }^{12}$ MLG according to Hooghe and Marks is an expandable concept, and in their 2001 contribution even the FOCJ model (functional,overlapping, competing jurisdiction) from Frey and Eichenberger (1995) was integrated as type II of governance (type I is the classical federalism).
} 
selfless as it may seem. Since the lower levels have a better image and find higher trust among the citizen, cooperating with them will exert positive side effects on the EU as a whole and especially on the Commission.

Based on these assumptions and the reasoning above, we use a somewhat extended version of the Article 20 (2) of the German Grundgesetz (Basic Law) as background methodology of our model: "All state authority emanates from the people. It is exercised by the people by means of elections and votings and by separate legislative, executive and judicial organs." What the article explicitly does not say is that the authority of the state can emanate from the people, directly or indirectly. In our interpretation this means that every jurisdiction at each level can exert state authority (including the top level, which is controversial concerning the EU), and its legitimation is derived over and over again from the people (the European people in the EU case). This entails that summing up the populations of all jurisdictions at a certain level, we always arrive at the whole population of the system and use it as the basis of legitimization. Of course, this procedure cannot be found in reality, which is characterized by institutions that are legitimized by the delegation of power. As Schumpeter wrote $(1942,282)$ "voters do not decide issues". Nevertheless, each level has its very own characteristic which we will operationalize by the differing figures of the outvoted.

Now, assume a four-level governance system where levels from top to bottom are supra-national $(\mathrm{SN})$, national $(\mathrm{N})$, regional $(\mathrm{R})$, and local $(\mathrm{L})$ as this fits best to the case of the EU. However, all our results are robust with respect to the number of levels. Independent of the number of levels the supra-national level always refers to the top level of any governance system and such the results for this level do. Analogously, all findings for the local level can be transferred to the lowest level of any multi-level system. In addition we assume, there is the same constant aggregate population (POP) on each of the four levels. This is a necessary assumption to exclude additional population effects which, as we will see, play an important role analyzing regime satisfaction. We postulate having one political jurisdiction at the top level, two political jurisdictions at the national level, four political jurisdictions at the regional level and eight at the local level, which forms a symmetrical structure. ${ }^{13}$ Jurisdictions at the same level are identical in the number of voters. ${ }^{14}$ For the sake of simplicity we assume the population of the local-level jurisdictions to be an even number. This assumption helps us to avoid rounding procedures and makes POP a number that is a multiple of $16 .{ }^{15}$ However, since population numbers

\footnotetext{
13 Our results also hold for any (even or uneven) number of jurisdictions on the various levels as long as the total number of voters is the same at each level and jurisdictions of one level are identical with respect to the number of voters.

14 This is a major but necessary simplification, of course as far as it excludes any migration processes between local areas, according to the Tiebout mechanism of voting by feet (Tiebout 1956) and the vast amount of subsequent literature dealing with it.

15 The reason is that under the assumption of the number of people in a local jurisdiction to be even, this number must be divisible by 2 , the respective number must be divisible by 4 at the regional level, by 8 at the national level and by 16 at the SN level.
} 
are quite high rounding an uneven number to the next highest even number only leads to a small approximation error.

Political decisions in our model are always between two alternatives, and this constitutes a 'yes-or-no' decision with regard to a specific political problem. Since we try to answer the question of what levels and how many jurisdictions at each level should be intertwined in a political decision if the goal is to minimize the number of the outvoted, we denote the number of intertwined jurisdictions at the four levels by $\mathrm{m}_{\mathrm{SN}} \in\{0,1\}, \mathrm{m}_{\mathrm{N}} \in\{0,1,2\}, \mathrm{m}_{\mathrm{R}} \in\{0,1, \ldots, 4\}$, and $\mathrm{m}_{\mathrm{L}} \in\{0,1, \ldots, 8\}$. The decision process can imply political intertwinings between jurisdictions at the same level (horizontal intertwinings), intertwinings between different levels encompassing the same space and population (vertical intertwinings), and intertwinings between different levels including complementary subsets of space and population (diagonal intertwinings). Obviously, there can also be a combination of horizontal, vertical, and diagonal intertwinings. To clarify this let us take up again the EU case from before. As we know from the Eurobarometer data from before the EU Commission has a comparatively bad image in the European public and the images of the jurisdictions are becoming the better the lower the level and the nearer they are to the citizens. On the other hand, our model will show that it always pays for the top level to cooperate with as much local jurisdictions at the local level as possible if it strives for minimizing the losers or increasing regime satisfaction. So, the EU Commission could kill two birds with one stone: the loser-minimizing strategy will be helpful in letting the European political regime appear more democratic and citizen-orientated via borrowed legitimacy, and the Commission at the top level could benefit a lot by image spill overs from lower levels. All that has to be found is an optimal structure of intertwinings which play the central role in our model.

It is important to note, however, that not all combinations make sense for all kinds of political decision. In this respect two types of decisions can be distinguished. Whenever a political decision concerns a project that can be realized at several levels independently and simultaneously, all kinds of intertwinings are logically and practically possible. This is true for Pennock's original example of the election of governments in which separate governments are elected in parallel for all jurisdictions. It would also be true for all projects or rules that can be implemented at an upper and a lower level at the same time, such as decisions on local, regional, and national schools, theatres etc. Whenever the decision is about a general rule or a project that cannot be in place for the same space and population at the same time, purely vertical intertwinings do not make sense. An example would be a decision on whether smoking is permitted in public spaces. This decision cannot be taken vertically intertwined at two or more levels, as the result cannot be valid for the same population and space at the same time (given heterogeneous preferences and different majorities at the levels). In political practice this problem is tackled by particular allocations of competences to the different levels. However, we neglect this problem and perform the calculations with regard to all possible combinations: first of all, because for many decisions all combinations are possible; and second, because this does not affect the general results with respect to the gains from federalism if a multi-level decision system makes sense. 
To derive the maximum number of the outvoted (MNO) for each jurisdiction we first focus on the population size pop $i, i \in\{S N, N, R, L\}$ of each jurisdiction. As the total population is the same at each level and numbers of jurisdictions are known it is easy to see that

$$
\operatorname{pop}_{\mathrm{SN}}=\mathrm{POP}, \quad \operatorname{pop}_{\mathrm{N}}=\frac{1}{2} \cdot \mathrm{POP}, \quad \operatorname{pop}_{\mathrm{R}}=\frac{1}{4} \cdot \mathrm{POP} \quad \text { and } \quad \operatorname{pop}_{\mathrm{L}}=\frac{1}{8} \cdot \mathrm{POP} .
$$

At the $\mathrm{SN}$ level the maximum number of the outvoted is given by $\mathrm{MNO}_{\mathrm{SN}}=$ $1 / 2 \cdot$ POP -1 which has already been recognized by Pennock $(1959,155)$. This is just half the population of the SN level minus unity implying that we exclude the case of equal votes for the alternatives from our model. This is close to reality for a majority has to be found for one of the alternatives in the end. Analogously, the maximum number of the outvoted at the other three levels is

$$
\mathrm{MNO}_{\mathrm{N}}=\frac{1}{4} \cdot \mathrm{POP}-1, \quad \mathrm{MNO}_{\mathrm{R}}=\frac{1}{8} \cdot \mathrm{POP}-1 \quad \text { and } \quad \mathrm{MNO}_{\mathrm{L}}=\frac{1}{16} \cdot \mathrm{POP}-1 .
$$

An institutional set up may be given by $\left(\mathrm{m}_{\mathrm{SN}}, \mathrm{m}_{\mathrm{N}}, \mathrm{m}_{\mathrm{R}}, \mathrm{m}_{\mathrm{L}}\right)$ where the ' $\mathrm{m}$ ' denotes the number of jurisdictions taking part in the process of solving a political problem. Thus, for example $(1,0,2,1)$ means that the top level, no national governments, two regional jurisdictions and one local jurisdiction are interwoven in the decision process. With this in mind, we can define the maximum number of the outvoted for any institutional set up by

$$
\begin{aligned}
\mathrm{MNO}= & \mathrm{m}_{\mathrm{SN}} \cdot\left(\frac{1}{2} \cdot \mathrm{POP}-1\right)+\mathrm{m}_{\mathrm{N}} \cdot\left(\frac{1}{4} \cdot \mathrm{POP}-1\right)+\mathrm{m}_{\mathrm{R}} \cdot\left(\frac{1}{8} \cdot \mathrm{POP}-1\right) \\
& +\mathrm{m}_{\mathrm{L}} \cdot\left(\frac{1}{16} \cdot \mathrm{POP}-1\right) \\
= & \frac{1}{2} \cdot\left(\mathrm{m}_{\mathrm{SN}}+\frac{1}{2} \cdot \mathrm{m}_{\mathrm{N}}+\frac{1}{4} \cdot \mathrm{m}_{\mathrm{R}}+\frac{1}{8} \cdot \mathrm{m}_{\mathrm{L}}\right) \cdot \mathrm{POP}-\left(\mathrm{m}_{\mathrm{SN}}+\mathrm{m}_{\mathrm{N}}+\mathrm{m}_{\mathrm{R}}+\mathrm{m}_{\mathrm{L}}\right)
\end{aligned}
$$

Evidently, the absolute maximum number of the outvoted increases in the total population POP. The existence of a supra-national level, i.e., an increase of $\mathrm{m}_{\mathrm{SN}}$ from 0 to 1 , consequently leads to an increase in the MNO by $1 / 2$. POP -1 . Although there is also such an increasing effect when the number of the intertwined jurisdictions at the other levels grows, these effects are far smaller with $1 / 4 \cdot \mathrm{POP}-1,1 / 8 \cdot \mathrm{POP}-1$ and $1 / 16 \cdot$ POP -1 for the national, regional and local levels.

Since the total number of the maximum outvoted is not so meaningful, we focus on the relative number of the outvoted (RNMO) with regard to the population intertwined. The size of the intertwined population (IP) for any institutional set up, therefore, is

$$
\begin{aligned}
\mathrm{IP} & =\mathrm{m}_{\mathrm{SN}} \cdot \mathrm{POP}+\mathrm{m}_{\mathrm{N}} \cdot \frac{1}{2} \cdot \mathrm{POP}+\mathrm{m}_{\mathrm{R}} \cdot \frac{1}{4} \cdot \mathrm{POP}+\mathrm{m}_{\mathrm{L}} \cdot \frac{1}{8} \cdot \mathrm{POP} \\
& =\left(\mathrm{m}_{\mathrm{SN}}+\frac{1}{2} \cdot \mathrm{m}_{\mathrm{N}}+\frac{1}{4} \cdot \mathrm{m}_{\mathrm{R}}+\frac{1}{8} \cdot \mathrm{m}_{\mathrm{L}}\right) \cdot \mathrm{POP} .
\end{aligned}
$$

This is just the size of the population of each jurisdiction at each level multiplied by the number of jurisdictions that are interwoven and represents the specific decision-making structure for a specific political problem. 
Table 4 Illustration of the model set up

\begin{tabular}{|c|c|c|c|c|c|c|c|c|}
\hline \multicolumn{4}{|c|}{ Supra national } & \multicolumn{5}{|l|}{$80(41: 39)$} \\
\hline National & & \multicolumn{3}{|c|}{$40(21: 19)$} & \multicolumn{4}{|c|}{$40(21: 19)$} \\
\hline Regional & & $20(11: 9)$ & & $20(11: 9)$ & $20(11: 9)$ & & $20(11: 9)$ & \\
\hline Local & $10(6: 4)$ & $10(6: 4)$ & $10(6: 4)$ & $10(6: 4)$ & $10(6: 4)$ & $10(6: 4)$ & $10(6: 4)$ & $10(6: 4)$ \\
\hline
\end{tabular}

Now we can define the relative number of the maximum outvoted as the fraction of MNO and IP

$$
\begin{aligned}
\mathrm{RNMO}=\frac{\mathrm{MNO}}{\mathrm{IP}} & =\frac{\frac{1}{2} \cdot\left(\mathrm{m}_{\mathrm{SN}}+\frac{1}{2} \cdot \mathrm{m}_{\mathrm{N}}+\frac{1}{4} \cdot \mathrm{m}_{\mathrm{R}}+\frac{1}{8} \cdot \mathrm{m}_{\mathrm{L}}\right) \cdot \mathrm{POP}-\left(\mathrm{m}_{\mathrm{SN}}+\mathrm{m}_{\mathrm{N}}+\mathrm{m}_{\mathrm{R}}+\mathrm{m}_{\mathrm{L}}\right)}{\left(\mathrm{m}_{\mathrm{SN}}+\frac{1}{2} \cdot \mathrm{m}_{\mathrm{N}}+\frac{1}{4} \cdot \mathrm{m}_{\mathrm{R}}+\frac{1}{8} \cdot \mathrm{m}_{\mathrm{L}}\right) \cdot \mathrm{POP}} \\
& =\frac{1}{2}-\frac{\left(\mathrm{m}_{\mathrm{SN}}+\mathrm{m}_{\mathrm{N}}+\mathrm{m}_{\mathrm{R}}+\mathrm{m}_{\mathrm{L}}\right)}{\left(\mathrm{m}_{\mathrm{SN}}+\frac{1}{2} \cdot \mathrm{m}_{\mathrm{N}}+\frac{1}{4} \cdot \mathrm{m}_{\mathrm{R}}+\frac{1}{8} \cdot \mathrm{m}_{\mathrm{L}}\right) \cdot \mathrm{POP}} .
\end{aligned}
$$

Since POP appears in the denominator of the second term, the size of the maximum outvoted increases not only in absolute but also in relative terms in the total population POP. Thus, an increasing population of the whole system (an enlargement of the EU, for instance) increases the relative number of the maximum outvoted as well.

To make things clearer, we present an example, set $\mathrm{POP}=80$ and derive the RNMO for different set ups. Table 4 illustrates the model.

The first number always gives the population size of the jurisdiction and the ratio in brackets gives the worst (lowest) voting relation regarding the number of outvoted. With regard to the numbers in brackets some explanation seems necessary. One could be inclined to think that since there are eight local jurisdictions with a 6:4 majority, the majority at the top of the system should be 48:32 instead of 41:39. However, we argued above that although adding up the populations of all jurisdictions at a certain level always leads to the whole population of the system, each level has its 'very own characteristic' which is operationalized by the differing figures of the outvoted. Since every citizen of the country appears on all four levels we expect from them to consider the same problem or project from the differing perspectives of a local, regional, and national or even supranational citizen. This implies that a 6:4 majority at the local level must not necessarily lead to a 48:32 majority at the top due to varying perspectives and preferences at the different levels. ${ }^{16}$ An example could be a national nuclear waste dump. As local citizen it seems plausible that a majority would not like it near to their homes, as a national citizen it should be clear to a majority that such a nuclear waste dump must be found somewhere, and as a regional citizen (state level) the same would hold but precisely 'not in my backyard'. Thus there could be varying majorities and minorities at the different levels. This case of unstable preferences is not the central point here, however: in the essence, it is not the preferences we are

\footnotetext{
16 This is not to say that 41:39 will be the natural outcome of such considerations for the top level. It is only the worst (lowest) winner loser relation (1.05) possible within a continuum ranging up to 1.5 for 48:32.
} 
interested in but the hypothetical maximum number of outvoted regardless of whether the losers or winners group is identical at the various levels. ${ }^{17}$

Now, focusing on horizontal intertwinings first and assuming that all jurisdictions at one level are intertwined we find ${ }^{18}$ :

- At the national level there is just one intertwining with an RNMO of 38 out of 80 $(47.50 \%)$. This bilateral club is better than a central decision at the top level with a RNMO of $48.75 \%$.

- At the regional level the RNMO is $45 \%$.

- Analogously, at the local level the RNMO is $40 \%$.

This result is exactly what Oates' decentralization theorem says. It is also in line with the principle of subsidiarity if we focus on the optimal supply of public goods. However, this result is by no means surprising, and we know from other studies (Schneider and Zimmermann 2009) that the gains from federalism, measured as the reduction in the number and share of the outvoted compared with a pure top-level decision, is inversely related to the population within the aggregate voting system; in the case of the EU and ceteris paribus a potential further enlargement would definitely reduce the gains from federalism.

However, since vertical and diagonal intertwinings are clearly more interesting, we concentrate on them in the following. The model allows for single, double and threefold intertwinings. In contrast to the horizontal case it is also important how many of the jurisdictions at each level are intertwined. Therefore, in a kind of polar approach we distinguish between the case where only one jurisdiction of the relevant levels is intertwined and the case where all jurisdictions of the relevant levels are intertwined. The results for the RNMO in our example with POP $=80$ are given in Tables 5, 6, and comparing the two columns, it is apparent that RNMO

\footnotetext{
17 An intriguing point was raised by a referee concerning the problem of the nuclear waste dump: Considering a 2 stage structure of national and regional/local jurisdictions (lets say 4 entities) the outcome depends on prior information on the location of the plant before voting: if the people are uncertain about the location a majority would vote against the plant cause it could be in their backyard, if they are relatively certain that it will be in region A (as in the Gorleben case in Germany at the time being) the outcome would be 60:20. Furthermore, assuming a majority in favor of a national dump the structure of vertical intertwinings implies that the regional jurisdictions (uncertainty; not in my backyard) would vote against it so that the project will not be implemented. The consequence is that, in practice, there will not be any outvoted at the national level anymore. The argument is striking as long as thoroughly selfish individuals are assumed and we depart from the notion that every level has its own characteristic of interests and voting which is inspired by the famous Margolis' model (1982) of individuals with manifold private and public roles. Solving this dilemma would require a social rule like that majority decisions at higher levels break majority decisions at lower levels, and a solution can be traced back to Buchanan and Tullock (1962) constituting a unanimously agreed decision rule so that no individual can complain afterwards that the results were against its preferences.

18 In the case of horizontal intertwinings and due to the assumption of equal populations in the jurisdictions of a specific level it does not matter how many jurisdictions are at each level: there will always be the same RNMO irrespective of the number of jurisdictions intertwined. Furthermore, according to our numerical structure above there cannot be any RNMO in the horizontal case smaller than $40 \%$ nor larger than $48.75 \%$. So, for example, decision making at the regional level would be $7.69 \%$ better than supra national decision making measured in RNMO and $11.11 \%$ worse than deciding at the local level but on a centralism (100) federalism (0) scale regional decision making would score 57 points.
} 
Table 5 RNMOs of different set ups

Table 6 Ranking of the RNMOs

\begin{tabular}{|c|c|c|c|}
\hline \multicolumn{2}{|c|}{ One jurisdiction per level } & \multicolumn{2}{|c|}{ All jurisdictions per level } \\
\hline Set up & RNMO (\%) & Set up & RNMO (\%) \\
\hline \multicolumn{4}{|c|}{ Single intertwinings } \\
\hline$(1,1,0,0)$ & 48.33 & $(1,2,0,0)$ & 48.13 \\
\hline$(1,0,1,0)$ & 48.00 & $(1,0,4,0)$ & 46.88 \\
\hline$(1,0,0,1)$ & 47.78 & $(1,0,0,8)$ & 44.38 \\
\hline$(0,1,1,0)$ & 46.67 & $(0,2,4,0)$ & 46.25 \\
\hline$(0,1,0,1)$ & 46.00 & $(0,2,0,8)$ & 43.75 \\
\hline$(0,0,1,1)$ & 43.33 & $(0,0,4,8)$ & 42.50 \\
\hline \multicolumn{4}{|c|}{ Double intertwinings } \\
\hline$(1,1,1,0)$ & 47.86 & $(1,2,4,0)$ & 47.08 \\
\hline$(1,1,0,1)$ & 47.69 & $(1,2,0,8)$ & 45.42 \\
\hline$(1,0,1,1)$ & 47.27 & $(1,0,4,8)$ & 44.58 \\
\hline$(0,1,1,1)$ & 45.71 & $(0,2,4,8)$ & 44.17 \\
\hline \multicolumn{4}{|c|}{ Threefold intertwinings } \\
\hline$(1,1,1,1)$ & 47.33 & $(1,2,4,8)$ & 45.31 \\
\hline
\end{tabular}

\begin{tabular}{llllll}
\hline Rank & \multicolumn{2}{l}{ One jurisdiction per level } & & \multicolumn{2}{l}{ All jurisdictions per level } \\
\cline { 2 - 3 } \cline { 5 - 6 } & Set up & RNMO (\%) & & Set up & RNMO (\%) \\
\hline 1 & $(0,0,1,1)$ & 43.33 & & $(0,0,4,8)$ & 42.50 \\
2 & $(0,1,1,1)$ & 45.71 & & $(0,2,0,8)$ & 43.75 \\
3 & $(0,1,0,1)$ & 46.00 & & $(0,2,4,8)$ & 44.17 \\
4 & $(0,1,1,0)$ & 46.67 & & $(1,0,0,8)$ & 44.38 \\
5 & $(1,0,1,1)$ & 47.27 & & $(1,0,4,8)$ & 44.58 \\
6 & $(1,1,1,1)$ & 47.33 & & $(1,2,4,8)$ & 45.31 \\
7 & $(1,1,0,1)$ & 47.69 & & $(1,2,0,8)$ & 45.42 \\
8 & $(1,0,0,1)$ & 47.78 & & $(0,2,4,0)$ & 46.25 \\
9 & $(1,1,1,0)$ & 47.86 & & $(1,0,4,0)$ & 46.88 \\
10 & $(1,0,1,0)$ & 48.00 & & $(1,2,4,0)$ & 47.08 \\
11 & $(1,1,0,0)$ & 48.33 & & $(1,2,0,0)$ & 48.13 \\
\hline
\end{tabular}

shrinks in general if all jurisdictions at the respective levels are intertwined instead of only one. As a hypothesis it can be stated that RNMO will decrease if the number of jurisdictions at an intertwined level grows.

Moreover, focusing on Table 6, for the case of 'one jurisdiction per level' the participation of the top level always leads to a higher RNMO. The worst case here beyond a pure top-level decision is the intertwining between the supra-national and the national levels (Table 6). The multi-level interactions, however, of three or four levels (again Table 6) are ranked in the middle and better as between the nation states and the supra-national level alone. The lowest RNMOs can be found for the interaction of regional and local levels, meaning that not only the number of 
jurisdictions intertwined at one level determines the RNMOs but also the systemic height of the level where these intertwinings occur.

Considering all jurisdictions of one level as intertwined (second column of Table 5) leads to similar results. Here, the RNMO is somewhat lower in general, and interactions that include the top level are slightly better than in the case where only one jurisdiction of each level is intertwined. This result is most striking if we compare the set ups $(1,0,0,1)$ and $(1,0,0,8)$, i.e., focusing on the interaction between the supra-national and local levels.

This example allows some preliminary conclusions: at the supra-national and the national levels we find the highest RNMO implying dissatisfaction and discomfort among the population just because the distance between these levels and the respective civil societies is quite large. Since an involvement of the top level always seems to be problematic, the question of an optimal multi-level strategy of the toplevel institution arises. ${ }^{19}$ Our example shows that 'national-level by-passing' and 'low-level interacting' seem to be good strategies. Comparing the two columns of the rank table (Table 6), avoiding interactions with the national level and seeking interactions with regional and local levels are preferable strategies. Nevertheless, if for any reason an exclusion of the national level is not possible, fostering the inclusion of local jurisdictions can serve as a compensating element. Here, the top level can gain remarkably by internalizing positive external effects with regard to information and image. This positive impact of an increased interaction with local jurisdictions on the RNMO is most evident if all jurisdictions at that level are included, which can be denoted strategically as 'more-is-better'. Such 'low-level interacting' decreases the RNMO in general but especially in case of an involvement of the local jurisdictions. ${ }^{20}$

Returning to our formal model, we are also able to present some generalized results. Comparing the effects of an increase in the number of intertwined jurisdictions, we focus on the difference quotient:

$\frac{\Delta \mathrm{RNMO}}{\Delta \mathrm{m}_{\mathrm{SN}}}$
$=\frac{8 \cdot\left(4 \cdot \mathrm{m}_{\mathrm{N}}+6 \cdot \mathrm{m}_{\mathrm{R}}+7 \cdot \mathrm{m}_{\mathrm{L}}\right)}{\left(8 \cdot \mathrm{m}_{\mathrm{SN}}+4 \cdot \mathrm{m}_{\mathrm{N}}+2 \cdot \mathrm{m}_{\mathrm{R}}+\mathrm{m}_{\mathrm{L}}\right) \cdot\left(8 \cdot \mathrm{m}_{\mathrm{SN}}+4 \cdot \mathrm{m}_{\mathrm{N}}+2 \cdot \mathrm{m}_{\mathrm{R}}+\mathrm{m}_{\mathrm{L}}+8\right) \cdot \mathrm{POP}}>0$

With regard to the relative number of the outvoted the existence of a supranational level undeniably increases the RNMO.

\footnotetext{
${ }^{19}$ Despite the fact that the primary goal is a political one, the process itself should be governed by economic reasoning: the output category is regime satisfaction, the production function implies the combination of various inputs in the form of the number of jurisdictions of different levels whose effectiveness with regard to minimizing the losers differs remarkably.

${ }^{20}$ As we already know this is very similar to what the EU Commission tries to achieve, at least partly, with its concept of new modes of multi level governance ('soft' non hierarchical political steering by the executive without law making) in its White Paper of 2001 (European Commission 2001). Thus, strategically seen, the Commission seems to be on a good track to intensify contacts with as many jurisdictions at the lower levels of the system as possible.
} 


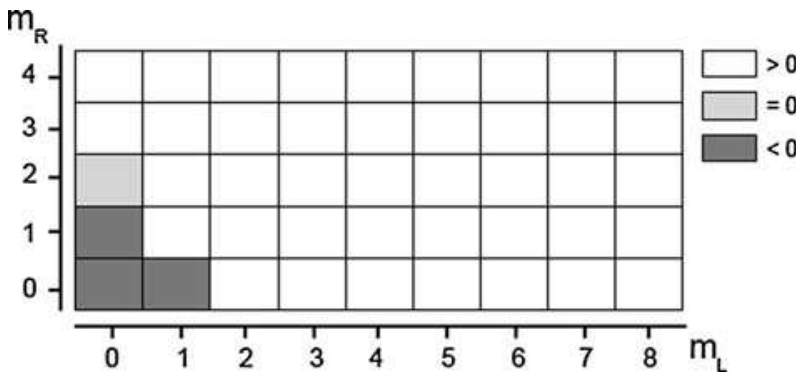

Fig. 1 Conditions for an increasing $(>0)$, decreasing $(<0)$ or constant $(0)$ effect of an additional national jurisdiction on RNMO

The effects of an increasing number of intertwined national or regional jurisdictions are more ambiguous, however. For the impact of an additional national jurisdiction on RNMO, we find

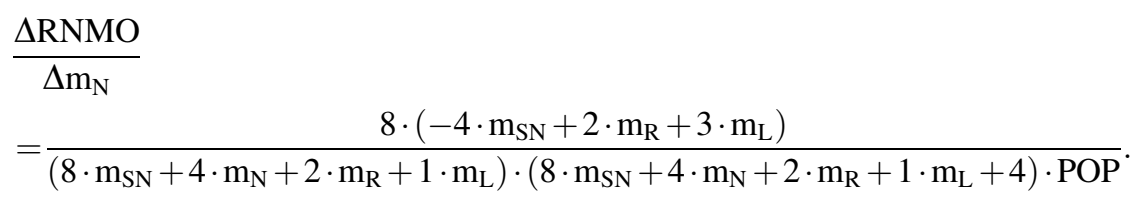

Taking the numerator into account RNMO decreases with an additional national jurisdiction if and only if

$$
-4 \cdot \mathrm{m}_{\mathrm{SN}}+2 \cdot \mathrm{m}_{\mathrm{R}}+3 \cdot \mathrm{m}_{\mathrm{L}}<0
$$

holds.

Concerning a possible enlargement of the system (e.g. new member countries of the EU) we set $\mathrm{m}_{\mathrm{SN}}=1$ and get $2 \cdot \mathrm{m}_{\mathrm{R}}+3 \cdot \mathrm{m}_{\mathrm{L}}-4<0$. We illustrate this condition in Fig. 1.

Obviously, in most cases the inclusion of an additional national jurisdiction in the decision process increases the RNMO. An additional national jurisdiction decreases RNMO only if no regional jurisdiction is intertwined and there is no more than just one local jurisdiction, or if there is one regional jurisdiction but no local one. To summarize, there are just three $\left(m_{L}, m_{R}\right)=\{(0,0),(0,1),(1,0)\}$ out of 45 set ups for which an increasing number of nations within the system decreases the RNMO, and we have to state that without doubt the enlargement process of the system increases the part of the population being in the minority position. Thus, a politically successful strategy of enlargement may bear the seed of failure in itself. ${ }^{21}$

\footnotetext{
21 This is surely not an empirical paper but we are grateful to a referee for proposing an empirical follow up: if the number of outvoted increases with the enlargement of the EU, then there should be a shrinking level of satisfaction with democracy in countries already in the EU. A quick glance at the data for Germany as a founding member and the most important country within the EU shows a highly significant negative correlation of 0.4758 between SWD and the cumulative population of the EU. Simple regression reveals that if the population of the EU increases by 1 mil. SWD (very and fairly satisfied) shrinks by 0.077 percentage points among the Germans (data from 1976 to 2010).
} 
Focusing on the influence of an additional regional jurisdiction intertwined on the RNMO we get:

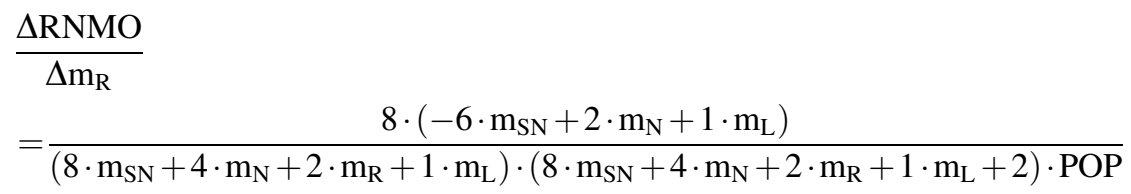

Again, the direction of change is not unambiguous. However, focusing on the numerator as before we see that an additional regional jurisdiction intertwined decreases the RNMO if and only if

$$
-6 \cdot \mathrm{m}_{\mathrm{SN}}+2 \cdot \mathrm{m}_{\mathrm{N}}+1 \cdot \mathrm{m}_{\mathrm{L}}<0
$$

holds. Taking the supra-national level as given, the condition simply becomes $2 \cdot \mathrm{m}_{\mathrm{N}}+1 \cdot \mathrm{m}_{\mathrm{L}}-6<0$. Again we can illustrate this condition as in Fig. 2.

As Fig. 2 shows there is a deadlock-situation: the number of cases where a growing number of intertwined regions increases the RNMO is just as big as its counterpart (12:12 out of 24). Comparably, an additional region intertwined decreases the RNMO in a much higher frequency of cases than an additional nation within the system.

The effect of an increasing number of local jurisdictions, however, is unambiguous.

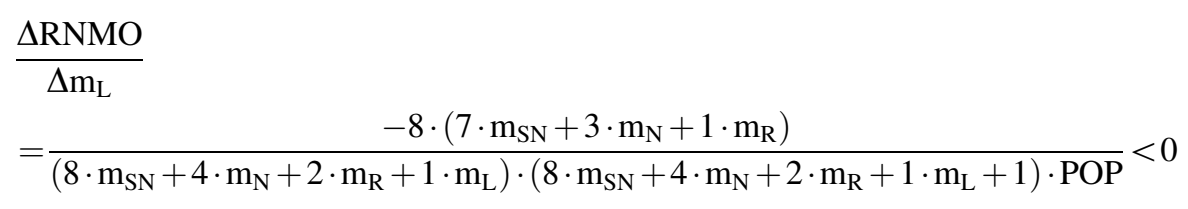

Focusing again on the numerator and setting $\mathrm{m}_{\mathrm{SN}}=1$, we get $3 \mathrm{~m}_{\mathrm{N}}+1 \mathrm{~m}_{\mathrm{R}}>-7$ which is always fulfilled. Thus, an additional local jurisdiction intertwined always decreases the RNMO.

To summarize, although there is a large public support for the enlargement strategy 'deepening and widening' (Ruiz-Jiménez and Torreblanca 2008) our analysis leads to more complex results: the impact of an additional national or regional jurisdiction on the RNMO depends on the already existing intertwined

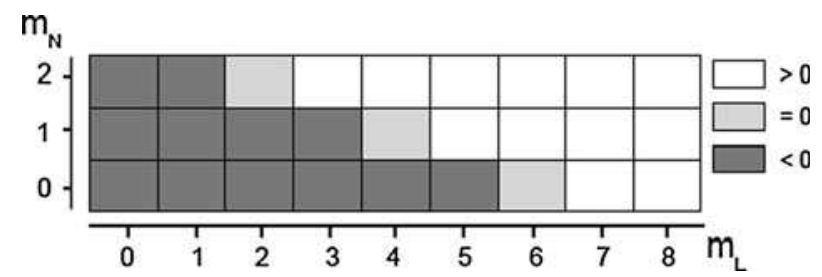

Fig. 2 Conditions for an increasing $(>0)$, decreasing $(<0)$ or constant $(0)$ effect of an additional regional jurisdiction on the RNMO 
jurisdictions and, therefore, can be negative or positive. However, an additional local jurisdiction always reduces the RNMO. Therefore, and as a political consequence, a negative effect of an enlargement of the total system and thus a growth in population size on the RNMO is best compensated for by an increasing number of local jurisdictions being intertwined. In an empirical study on the EU enlargement it would be necessary to separate the deepening effect from the widening effect. Unfortunately, as far as we know, such an empirical analysis does not exist until now.

\section{Conclusion}

If policy aims at the reduction of the number of the outvoted since that improves citizens' satisfaction with the political system, then the strategic variables influencing the number of the outvoted need to be discussed. To simplify the model we proposed a four-stage governance system in which every level derives its legitimization from the whole population just as the same citizen appears as a citizen of the European Union, a citizen of Germany, a citizen of North RhineWestphalia and a citizen of Cologne. We have assumed further that if a project touches on two or more levels it must find an electoral majority in the jurisdictions of the same two or more levels. Since we focus primarily on the outvoted or the minorities in such elections, we have chosen the indicator of the maximum number of the outvoted as a directly evident characteristic. Furthermore, we have simplified the model by the assumption that the jurisdictions at each level are identical, thus having the same number of voters.

The results of the model and its variations are predominantly conclusive: a growing system's population (enlargement) generally leads to an increase in the share of the outvoted. Concerning the pure horizontal intertwinings of jurisdictions the model reveals a constant share of the maximum number of the outvoted at a specific level: the degree of political intertwinings at the single levels (the number and size of clubs) has no influence on the relative maximum number of the outvoted. However, the number of the maximum outvoted is higher on the upper levels of the system. Thus, 'low-level interacting', i.e., inclusion of the lower levels in decisionmaking, is an optimal strategy to reduce the number of the outvoted.

The vertical intertwinings are even more interesting. Here in general a 'moreis-better' strategy, i.e., the inclusion of all jurisdictions of one level, works better with regard to the minimization of the number of the outvoted than including just one jurisdiction of a specific level. However, the effects are not unambiguous. More precisely, in an existing system the additional inclusion of national and regional jurisdictions can increase or decrease the relative number of the outvoted. These effects strongly depend on the shape of the existing system, i.e., on the number and levels of the jurisdictions already involved. In contrast, the effect of an additional local jurisdiction is always to lower the relative number of the outvoted and, therefore, it can compensate for the negative effects exerted by intertwined jurisdictions of higher levels. Thus, intertwining and network building should always start at the lowest level with the highest number of jurisdictions. This also 
means that it is always better for the relative number of the maximum outvoted to have more intertwined jurisdictions in the system at a lower level than less. If this first-best strategy may not be viable for some reasons and if there is a necessity to involve jurisdictions from higher levels as a second-best solution, the result will always be better than having less intertwined jurisdictions. However, the positive impact of an additional jurisdiction intertwined on the relative number of the maximum outvoted is the smaller the higher the level of the additional jurisdiction.

Summing up, the multi-level problem seen from the supra-national level is a twodimensional one. On the one hand, the core question clearly is the inclusion of levels and of interactions with them. On the other hand, it is the number of levelspecific jurisdictions intertwined. We have stated that in the end an optimal strategy of 'national-level bypassing', 'low-level interacting', and 'more-is-better' could be recommended for the top-level institution. We have made clear in our theoretical analysis that in general it is always better to have more level-specific jurisdictions interacting with the top level. We have also clarified that a situation close to the optimum can only be realized by low-level interacting thus compensating for deficits of legitimation at higher levels of the system.

\section{References}

Anderson, C. J., \& LoTempio, A. J. (2002). Winning, losing and political trust in america. British Journal of Political Science, 32, 335351.

Anderson, C. J., \& Tverdova, Y. V. (2001). Winners, losers and attitudes about government in contemporary democracies. International Political Science Review, 22, 321338.

Anderson, C. J., Blais, A., Bowler, S., Donovan, T., \& Listhaug, O. (2005). Loser's consent: Elections and democratic legitimacy. Oxford: Oxford University Press.

Anscombe, G. E. M. (1976). On frustration of the majority by fulfilment of the majority's will. Analysis, $36,161168$.

Buchanan, J. M. (1965). An economic theory of clubs. Economica, 32, 114.

Buchanan, J. M., \& Tullock, G. (1962). The calculus of consent: Logical foundations of constitutional democracy. Ann Arbor, Michigan: University of Michigan Press.

Bueno de Mesquita, B., Smith, A., Siverson, R. M., \& Morrow, J. D. (2003). The logic of political survival. Cambridge: MIT Press.

Castillo, A. M. J. (2006). Institutional performance and satisfaction with democracy. A comparative analysis. Paper presented at the comparative study of the electoral systems plenary, Seville, March 2006. Granada: Department of Sociology, University of Granada.

Commission of the European Communities. (2001). European Governance. A white paper, COM (2001) (p. 428), Brussels.

Curini, L., Jou, W., \& Memoli, V. (2010). Satisfaction with democracy and the Winner Loser Debate: The role of policy preferences and past experience. Working paper 3/2010. Dipartimento di Studi Sociali e Politici, Univerita degli Studi di Milano, Milan.

Cusack, T. R. (1999). The shaping of popular satisfaction with government and regime performance in Germany. British Journal of Political Science, 29, 641672.

Dalton, R. J. (1999). Political support in advanced industrial democracies. In P. Norris (Ed.), Critical citizens: Global support for democratic governance. New York: Oxford University Press.

Easton, D. (1975). A re assessment of the concept of political support. British Journal of Political Science, 5, 435457.

European Commission. (2009a). Eurobarometer 70. Public opinion in the European Union. First results. Brussels. http://ec.europa.eu/public opinion/archives/eb/eb70/eb70 first en.pdf. 
European Commission. (2009b). Special Eurobarometer 307. The role and impact of local and regional authorities within the European Union. Brussels. http://ec.europa.eu/public opinion/archives/ ebs/ebs 307 en.pdf.

Frey, B., \& Eichenberger, R. (1995). Competition among Jurisdictions. In L. Gerken (Ed.), Competition among institutions (pp. 209 229). London: MacMillan.

Frey, B. S., \& Stutzer, A. (2001). Happiness and economics: How the economy and institutions affect human well being. Princeton: Princeton University Press.

Frey, B. S., \& Stutzer, A. (2004). Beyond outcomes: measuring procedural utility. Oxford Economic Papers, 57, 90111.

Haerpfer, C. W. (2007). Political support for democracy and safisfaction with democracy in European political systems. Paper presented at the Midterm Conference on European Citizenship Challenges and consequences, Roskilde University, Denmark. June 2007. Department of politics and international relations, University of Aberdeen, Aberdeen

Holzinger, K. (2000). Optimale Regulierungsräume für Europa. Flexible Kooperation territorialer und funktionaler Jurisdiktionen. In C. Landfried (Ed.), Politik in einer entgrenzten Welt (pp. 153 180). Berlin: Verlag Wissenschaft und Politik.

Holzinger, K. (2008). Transnational common goods: Strategic constellations, collective action problems, and multi level provision. New York: Pelgrave Macmillan.

Hooghe, L., \& Marks, G. (2001). Multi level governance and European integration. Lanham: Rowman \& Littlefield.

Hooghe, L., \& Marks, G. (2003). Unraveling the central state, but how? Types of multi level governance. American Political Science Review, 97, 233243.

Kahlenborn, W., \& Zimmermann, K. W. (1994). Umweltföderalismus. Einheit und Einheitlich keit in Deutschland und Europa. Berlin: Edition sigma.

Margolis, H. (1982). Selfishness, Altruism, and Rationality. New York: Cambridge University Press.

Marks, G., Hooghe, L., \& Blank, K. (1996). European Integration from the 1980 s: State Centric v. Multi level Governance. Journal of Common Market Studies, 34, 341378.

Merlin, V., \& Valogne, F. (2004). The impact of indifferent voters on the likelihood of some voting paradoxes. Mathematical Social Sciences, 48, 343361.

Nadeau, R., \& Blais, A. (1993). Accepting the election outcome: The effect of participation on loser's consent. British Journal of Political Science, 23, 553563.

Norris, P. (Ed.). (1999). Critical citizens: Global support for democratic government. New York: Oxford University Press.

Oates, W. E. (1972). Fiscal federalism. London: Harcourt Brace.

Oates, W. E. (1999). An essay on fiscal federalism. Journal of Economic Literature, 37, 11201149.

Olson, M. (1969). The principle of fiscal equivalence: The division of responsibilities among different levels of government. American Economic Review, Papers and Proceedings, 59, 479487.

Pennock, J. R. (1959). Federal and unitary government disharmony and frustration. Behavioral Science, 4, 147157.

Puchala, D. (1972). Of blind men, elephants and international integration. Journal of Common Market Studies, 10, 267284.

Rabushka, A., \& Shepsle, K. (1972). Politics in plural societies: A theory of democratic instability. Columbus, Ohio: Charles E. Merrill.

Riker, W. H. (1964). Federalism: Origin, operation, significance. Brown, Boston: Little.

Riker, W. H. (1969). Six books in search of a subject or does federalism exist and does it matter? Comparative Politics, 2, 135146.

Riker, W. H. (1987). The development of American federalism. Boston: Kluwer.

Riker, W. H. (1996). European federalism: The lesson of past experience. In J. J. Hesse \& V. Wright (Eds.), Federalizing Europe? The costs, benefits, and preconditions of federal political systems (pp. 9 24). Oxford: Oxford University Press.

Riker, W. H., \& Schaps, R. (1957). Disharmony in Federal government. Behavioral Science, 2, 276290.

Rose Ackerman, S. (1981). Does federalism matter? Political choice in a federal republic. Journal of Political Economy, 89, 152165.

Ruiz Jiménez, A. M., \& Torreblanca, J. I. (2008). Is there a trade off between deepening and widening? What do Europeans think? Working paper, European policy institutes network, no. 17.

Scharpf, F. W. (1988). The joint decision trap. Lessons from German federalism and European integration. Public Administration, 66, 239278. 
Scharpf, F. W. (2001). European Governance: Common concerns vs. the challenge of diversity, MPIfG Working Paper 01/6, September 2001, Köln.

Schneider, A., \& Zimmermann, K. W. (2009). Mehr zu den politischen Segnungen von Föderalismus, Working paper series 92, Department of Economics, Helmut Schmidt University, Hamburg.

Schumpeter, J. A. (1942). Capitalism, socialism and democracy. New York: Harper.

Tiebout, C. (1956). A pure theory of local expenditures. Journal of Political Economy, 64, 416424.

Tsebelis, G. (2002). Veto players. How political institutions work. Princeton: Princeton University Press.

Volden, C. (2004). Origin, operation, and significance: The federalism of William H. Riker. Publius. The Journal of Federalism, 34, 89107.

von Hayek, F. A. (1968). Der Wettbewerb als Entdeckungsverfahren. Kieler Vorträge N.F. 56. Kiel: Institut für Weltwirtschaft.

Wagner, R. E. (1971). The fiscal organization of American federalism. Chicago: Markham.

Wagner, R. E. (1973). The public economy. Chicago: Markham.

Wagner, R. E. (2001). Competitive federalism in institutional perspective. In D. P. Racheter \& R. E. Wagner (Eds.), Federalist government in principle and practice (pp. 19 37). Boston: Kluwer.

Wagner, R. E. (2007). Fiscal sociology and the theory of public finance. An exploratory essay. Cheltenham, UK: Elgar.

Wagner, A. F., Schneider, F., \& Halla, M. (2009). The quality of institutions and satisfaction with democracy in Western Europe a panel analysis. European Journal of Political Economy, 25, 3041.

Wallace, H. (2005). An Institutional anatomy and five policy modes. In H. Wallace, W. Wallace, \& M. A. Pollack (Eds.), Policy making in the European Union (5th ed., pp. 49 90). New York: Oxford University Press.

Zimmermann, K. W., \& Schemm Gregory, R. (2005). Eine Welt voller clubs. Zeitschrift für Wirtschaft spolitik, 54, 230261. 